\title{
Comorbidity profile in dementia with Lewy bodies versus Alzheimer's disease: a linkage study between the Swedish Dementia Registry and the Swedish National Patient Registry
}

Seyed-Mohammad Fereshtehnejad', Soheil Damangir ${ }^{1}$, Pavla Cermakova ${ }^{2,3}$, Dag Aarsland ${ }^{2,4}$, Maria Eriksdotter ${ }^{1,5}$ and Dorota Religa ${ }^{2,5^{*}}$

\begin{abstract}
Introduction: Compared to Alzheimer's disease (AD), dementia with Lewy bodies (DLB) is usually associated with a more complex clinical picture and higher burden of care. Yet, few investigations have been performed on comorbidities and risk factors of DLB. Therefore, we aimed to compare clinical risk factors and comorbidity profile in DLB and AD patients using two nationwide registries.
\end{abstract}

Methods: This is a linkage study between the Swedish dementia registry (SveDem) and the Swedish National Patient Registry conducted on 634 subjects with DLB and 9161 individuals with AD registered during the years 2007-2012. Comorbidity profile has been coded according to the International Classification of Diseases version 10 (ICD 10) in addition to the date of each event. The main chapters of the ICD-10, the Charlson score of comorbidities and a selected number of neuropsychiatric diseases were compared between the DLB and AD groups. Comorbidity was registered before and after the dementia diagnosis.

Results: "Mental and behavioral disorders", "diseases of the nervous system", "diseases of the eye and adnexa", diseases of the "circulatory", "respiratory", and "genitourinary" systems, "diseases of the skin and subcutaneous tissue" and "diseases of the musculoskeletal system and connective tissue" occurred more frequently in the DLB group after multivariate adjustment. Depression [adjusted $\mathrm{OR}=2.12(95 \% \mathrm{Cl} 1.49$ to 3.03$)$ ] and migraine [adjusted $\mathrm{OR}=3.65$ $(95 \% \mathrm{Cl} 1.48$ to 9.0$)$ ] were more commonly recorded before the diagnosis of dementia in the DLB group. Following dementia diagnosis, ischemic stroke [adjusted $\mathrm{OR}=1.89(95 \% \mathrm{Cl} 1.21$ to 2.96$)]$ was more likely to happen among the DLB patients compared to the AD population.

Conclusions: Our study indicated a worse comorbidity profile in DLB patients with higher occurrence of depression, stroke and migraine compared with the AD group. Deeper knowledge about the underlying mechanisms of these associations is needed to explore possible reasons for the different pattern of comorbidity profile in DLB compared to AD and their prognostic significance.

\footnotetext{
* Correspondence: dorota.religa@ki.se

2Division of Neurogeriatrics, Department of Neurobiology, Care Sciences, and Society, Center for Alzheimer Research, Karolinska Institutet, Stockholm,

Sweden

${ }^{5}$ Department of Geriatric Medicine, Karolinska University Hospital, Stockholm, Sweden

Full list of author information is available at the end of the article
} 


\section{Introduction}

Dementia with Lewy bodies (DLB) is the second most common type of degenerative dementia after Alzheimer's disease (AD) [1]. Compared with AD, DLB is associated with poorer prognosis, shorter time to nursing home admission, higher care burden and higher healthcare costs [2-4]. However, cognitive and functional decline do not seem to differ between these two groups [5]. In addition to a more complex clinical picture of DLB that is characterized by visual hallucinations, motoric symptoms, sleep disorders and autonomic dysfunction, comorbidities may be crucial predictors of worse outcomes in DLB patients. Comorbid diseases significantly increase utilization of healthcare resources [2], predict key outcomes of acute hospital care in older people [6] and are associated with a higher risk of death after dementia diagnosis [7].

Little attention has been paid to research on comorbidities and risk factors of DLB. Previous studies showed that occurrence of depression [8,9] and anxiety [10] is higher in DLB patients when compared with AD. Depression has been suggested as a risk factor for DLB [9] and was more likely to persist over time in DLB subjects compared with $\mathrm{AD}$ patients [11]. History of stroke and anxiety has been reported to occur more often in DLB patients than in healthy controls, but not in comparison with AD patients [9].

Correct assessment of risk factors and comorbidities is a central part of clinical management of DLB patients. Furthermore, understanding them may provide new insights into the underlying pathophysiology of DLB. In this study, capitalizing on two nationwide registries, we compared clinical risk factors and comorbidity profiles for $A D$ and DLB in 9,795 subjects, including 634 patients with DLB. To the authors' best knowledge this is one of the largest published DLB cohorts.

\section{Methods}

This study was performed by linking the Swedish Dementia Registry (SveDem) and the Swedish National Patient Registry. The personal identity number was used as the unique identifier for merging the two databases. Patients were followed-up until 31 December 2012.

\section{Swedish Dementia Registry}

SveDem is a nationwide registry that includes newly diagnosed dementia patients from Sweden [12]. SveDem is a web-based quality registry, initiated in 2007, to improve the quality of diagnostics work-up, treatment and care of dementia across the country [13]. The majority of patients are registered through specialist care units (memory clinics) and the type of dementia is recorded as earlyonset $\mathrm{AD}$, late-onset $\mathrm{AD}$, mixed $\mathrm{AD}$, vascular dementia, DLB, frontotemporal dementia, Parkinson's disease with dementia, unspecified dementia or others.
At the end of 2012, 58 specialist units (93\% of all in Sweden) and 659 primary care centers $(60 \%$ of all in Sweden) were affiliated with SveDem. Using an estimated incidence rate of 20,000 patients that develop dementia in Sweden each year [14], the approximate coverage of incident dementia cases in SveDem in 2012 was 36\%. However, the study population represents a census of all newly diagnosed dementia patients because all of those who referred to the registered centers were recruited.

This study population comprised only two subgroups, 634 individuals with DLB (DLB group) and 9,161 cases with $\mathrm{AD}$ (AD group), recruited during the years 2007 to 2012. Dementia was diagnosed according to the International Classification of Diseases (ICD) version 10 criteria [15]. In addition, McKeith criteria were used to diagnose DLB [16].

Information about age, sex, living conditions, medication profile, diagnosis of DLB and AD (ICD version 10 codes of G31.8 for DLB and G30.0 and G30.1 for AD), baseline Mini-Mental State Examination (MMSE) score [17] and date of referral for dementia work-up were obtained from the SveDem records.

\section{Swedish National Patient Registry}

The Swedish National Patient Registry is administered by the Swedish National Board of Health and Welfare, which covers inpatient care in Sweden to 1987 [18]. The doctor responsible for the patient determines the diagnoses in the registry based on clinical evaluations and laboratory assessments on that particular occasion of inhospital care. Diagnoses were coded using the latest version of the ICD according to the year of registration.

At the time of discharge, the physician registers a main diagnosis and one or more secondary diagnoses if applicable for each patient. A similar procedure is also performed through all outpatient clinics and afterwards. The diagnostic codes are sent by the hospitals and outpatient clinics to the National Board of Health and Welfare. Later, one main diagnosis and up to seven secondary diagnoses are registered together with demographics and administrative information such as hospital, clinic, dates of admission and discharge, surgical procedures and patient characteristics including age, sex and place of residence. Data obtained from 2000 to 2012 were used for this study.

\section{Comorbidity profile}

In addition to the main chapters of the ICD version 10 , another comparison was performed based on the comorbidity scoring of the ICD version 10 codes recommended by the Royal College of Surgeons called the Charlson Score [19]. The total Charlson score of comorbidities was calculated by counting the number of comorbidity categories without any preassigned weights [20]. Data on a selected list of neuropsychiatric diseases were also extracted 
from the Swedish National Patient Registry using the ICD version 10 codes as follows: depression (F32, F33), anxiety (F40, F41), behavioral disorders (F07, F10, F11, F12, F13, F14, F15, F16, F17, F18, F19, F53, F54, F59, F66, F68, F69, F98, R46), bipolar affective disorder (F31), sleep disorder (F51, G47), syncope (R55), ischemic stroke (I63, I64, I67, I69), cerebral hemorrhage (I60, I61, I62), epilepsy (G40), migraine (G43) and other types of headache (G44, R51). The time of registration was used to check whether the disease occurred before or after dementia diagnosis as well as to calculate the time intervals between the dates.

Since no information is available on the exact time when the symptoms started, we used the date of registration as the initial time point for dementia and the comorbidities. Therefore, if the date of registration for any of the comorbidities has been recorded prior to the date of registration in SveDem, we considered that comorbidity has occurred before dementia, and vice versa.

\section{Statistical analysis}

The mean (standard deviation (SD)) and frequency percentage (\%) were reported to describe quantitative and categorical variables. For univariate comparisons, the chi-square statistic and Fisher's exact test were used to compare the relative frequency of nominal variables (that is, sex, comorbidities) between the two study groups where appropriate. To compare the mean value of quantitative variables between the DLB and AD groups, either an independent-sample $t$ test or a Mann-Whitney $U$ test were used for normally or skewed distributions, respectively.

Further multivariate analysis was performed to adjust for the confounding effect of the baseline differences in age and sex between the DLB and AD groups. For this purpose, a binary logistic regression model was applied to evaluate the differences observed in the prevalence of different comorbidities between the DLB and AD groups adjusted for the baseline confounders. Afterwards, the adjusted odds ratio (OR) and its corresponding 95\% confidence interval $(\mathrm{CI})$ for each comorbidity were calculated. For the comorbidities that occurred before the date of referral for dementia, type of dementia (DLB vs. $\mathrm{AD})$ was considered the dependent variable. If the comorbid event happened after dementia diagnosis, the comorbidity was defined as the dependent variable and the type of dementia as a predictor in the multivariate model. In all analytical procedures, two-tailed $P<0.05$ was considered to show statistically significant difference. Data were analyzed using SPSS software version 22 (IBM Co., Chicago, IL USA).

\section{Ethical issues}

The regional Ethical Committee of Stockholm approved data collection (Drn. 2013/147-31/2), as well as the merging and the analytical procedures performed in this study. The patients were informed orally and in writing about SveDem and could decline participation. Data were coded and anonymized before statistical analysis.

\section{Results}

\section{Baseline characteristics}

A total number of 634 individuals with DLB and 9,161 AD patients were recruited. The DLB group consisted of 382 (60.3\%) males and 252 (39.7\%) females with a mean age of $76.5(\mathrm{SD}=7.1)$ years. The AD group comprised 3,188 (34.8\%) males and 5,973 (65.2\%) females with a mean age of $77.6(\mathrm{SD}=8.3$ ) years at the time of dementia diagnosis. Results of the Pearson chi-square test and the independent-samples $t$ test revealed that there were significantly more males $(P<0.001)$ and fewer old patients $(P<0.001)$ in the DLB group. Other baseline, demographic and medication characteristics of the two study groups are presented and compared in Table 1. The mean of the baseline MMSE score was quite similar in the DLB (21.4 $(\mathrm{SD}=5.0))$ and $\mathrm{AD}(21.5(\mathrm{SD}=5.0))$ groups $(P=0.593)$. However, in the DLB group the proportion of patients in nursing homes was larger than that in the $\mathrm{AD}$ group (11.8\% vs. $5.6 \%, P<0.001)$.

DLB patients were under treatment with a significantly higher number of medications $(4.7(\mathrm{SD}=3.0))$ compared with the AD group (3.7 ( $\mathrm{SD}=2.9)$ ). A multivariate Poisson regression model showed that DLB patients received a higher number of drugs $(B=0.268$ (95\% CI $=0.230$ to $0.307), P<0.001$ ) after adjustment for sex and age. While a similar proportion of patients were treated with cholinesterase inhibitors in both the DLB (73.6\%) and AD (72.7\%) groups $(P=0.272), N$-methyl $D$-aspartate antagonists (15.0\% vs. $9.9 \%)$, antidepressants (34.8\% vs. $26.3 \%)$, antipsychotics (16.3\% vs. $4.9 \%)$ and anxiolytics (13.3\% vs. $8.2 \%$ ) were significantly more often prescribed among the DLB group.

\section{International Classification of Diseases version 10 chapters}

Table 2 summarizes the comorbidity profile of the DLB and $A D$ patients based on the chapters of the ICD version 10 coding system. 'Mental and behavioral disorders' (66.1\%) and 'diseases of the eye and adnexa' (57.9\%) were the most common categories recorded for the DLB group apart from the 'diseases of the nervous system'; while among the AD patients 'diseases of the eye and adnexa' (47.9\%), 'diseases of the musculoskeletal system and connective tissue' (40.7\%) and 'diseases of the circulatory system' (40.3\%) were most commonly recorded as comorbid conditions. 'Mental and behavioral disorders', 'diseases of the nervous system', 'diseases of the eye and adnexa', diseases of the 'circulatory', 'respiratory', 'digestive' and 'genitourinary' systems and the 'diseases of the skin 
Table 1 Baseline, diagnostic and medication characteristics of the two study groups: cases suffering from dementia with Lewy bodies versus Alzheimer's disease patients

\begin{tabular}{|c|c|c|c|}
\hline Characteristic & $\begin{array}{l}\text { Dementia with Lewy bodies } \\
\qquad(n=634)\end{array}$ & $\begin{array}{l}\text { Alzheimer's disease } \\
\qquad(n=9,161)\end{array}$ & $P$ value \\
\hline \multicolumn{4}{|l|}{ Gender } \\
\hline Female & $252(39.7 \%)$ & $5973(65.2 \%)$ & \multirow[t]{2}{*}{$<0.001$} \\
\hline Male & $382(60.3 \%)$ & $3188(34.8 \%)$ & \\
\hline Age (years) & $76.5(7.1)$ & $77.6(8.3)$ & $<0.001^{b}$ \\
\hline MMSE score & $21.4(5.0)$ & $21.5(5.0)$ & $0.593^{b}$ \\
\hline Body mass index $\left(\mathrm{kg} / \mathrm{m}^{2}\right)$ & $24.4(4.1)$ & $24.3(4.1)$ & $0.565^{\mathrm{b}}$ \\
\hline \multicolumn{4}{|l|}{ Living place } \\
\hline Own house & $559(88.2 \%)$ & 8627 (94.4\%) & \multirow[t]{2}{*}{$<0.001$} \\
\hline Nursing home & $75(11.8 \%)$ & $512(5.6 \%)$ & \\
\hline \multicolumn{4}{|l|}{ Co-resident } \\
\hline Yes & $218(36.0 \%)$ & $3879(44.0 \%)$ & \multirow{2}{*}{$<0.001$} \\
\hline No & $387(64.0 \%)$ & $4938(56.0 \%)$ & \\
\hline \multicolumn{4}{|c|}{ Medication (at the time of diagnosis) } \\
\hline Cholinesterase inhibitors & $465(73.6 \%)$ & $6598(72.7 \%)$ & $0.272^{\mathrm{a}}$ \\
\hline NMDA antagonist & $95(15.0 \%)$ & $895(9.9 \%)$ & $<0.001^{\mathrm{a}}$ \\
\hline Antidepressants & $220(34.8 \%)$ & $2382(26.3 \%)$ & $<0.001^{a}$ \\
\hline Antipsychotics & $103(16.3 \%)$ & $447(4.9 \%)$ & $<0.001^{\mathrm{a}}$ \\
\hline Anxiolytics & $84(13.3 \%)$ & $747(8.2 \%)$ & $<0.001^{a}$ \\
\hline Hypnotics & $106(16.8 \%)$ & $1292(14.2 \%)$ & $0.065^{\mathrm{a}}$ \\
\hline Cardiovascular drugs & 365 (57.8\%) & $4825(53.2 \%)$ & $0.054^{\mathrm{a}}$ \\
\hline Total number of drugs & $4.7(3.0)$ & $3.7(2.9)$ & $<0.001^{b}$ \\
\hline
\end{tabular}

Data presented as number (\%) or mean (standard deviation). Statistically significant differences $(P<0.05)$ in bold. MMSE, Mini-Mental State Examination; NMDA, $N$-methyl D-aspartate. ${ }^{\mathrm{a}}$ Pearson chi-square statistic. ${ }^{\mathrm{b}}$ Independent-sample $t$ test.

and subcutaneous tissue' occurred more commonly in the DLB group based on the univariate comparisons.

As shown in Table 2, all univariate significant differences remained statistically significant after multivariate adjustment except for the 'diseases of the digestive system'. Moreover, DLB patients suffered more from the 'diseases of the musculoskeletal system and connective tissue' after adjustment for age and sex (adjusted OR = 1.19 (95\% $\mathrm{CI}=1.01$ to 1.41$)$ ). The greatest between-group differences in the ICD version 10 disease categories were observed in 'mental and behavioral disorders' (66.1\% vs. $38.7 \%$, adjusted $\mathrm{OR}=3.14 \quad(95 \% \mathrm{CI}=2.63$ to 3.75$))$, 'diseases of the nervous system' (88.0\% vs. $71.0 \%$, adjusted $\mathrm{OR}=2.78$ (95\% CI $=2.15$ to 3.58$)$ ) and 'diseases of the eye and adnexa' (57.9\% vs. $47.9 \%$, adjusted OR $=1.69$ $(95 \% \mathrm{CI}=1.42$ to 2.01$)$ ), all of which were more common in the DLB group.

Further subgroup analysis was performed to assess how patients' gender, level of cognition and living place might affect the differences in the comorbidity profile between the DLB and AD groups. As summarized in Table 3, some comorbidity categories such as 'mental and behavioral disorders' and 'diseases of the nervous system' were significantly more common in the DLB group among all of the subgroups regarding gender, cognition and living place (all $P<0.05$ ). On the other hand, 'diseases of the circulatory system' was significantly more prevalent in the DLB patients who were female $(46.8 \%$ vs. $38.6 \%, P=0.009)$, had $\mathrm{MMSE}<22(49.6 \%$ vs. $39.1 \%, P=0.001)$ and live in their own house (46.3\% vs. $40.2 \%, P=0.005)$.

Although 'diseases of the respiratory system' was more commonly recorded in the DLB patients with both MMSE $\geq 22(P=0.043)$ and MMSE $<22(P=0.018)$, with regard to gender and living place the difference was significant only among the males $(27.7 \%$ vs. $20.5 \%, P=0.001)$ and those who live in their own houses (22.9\% vs. $18.0 \%$, $P=0.004)$. Furthermore, 'diseases of the digestive system' (38.9\% vs. $30.3 \%, P=0.003$ ) and 'diseases of the musculoskeletal system and connective tissue' (45.6\% vs. $38.5 \%$, $P=0.022$ ) were significantly higher in the DLB group compared with the $\mathrm{AD}$ group only among the subgroup with MMSE $<22$ at the time of diagnosis.

\section{Charlson comorbidity scoring}

Comorbidity profiles of the DLB and AD patients using the Royal College of Surgeons Charlson categorization 
Table 2 Comorbidity profile of the patients with dementia with Lewy bodies versus Alzheimer's disease patients based on the chapters of the International Statistical Classification of Diseases and Related Health Problems, 10th Revision

\begin{tabular}{|c|c|c|c|c|c|c|c|c|}
\hline Chapter & Blocks & Title & $\begin{array}{c}\text { DLB } \\
(n=634)\end{array}$ & $\begin{array}{c}\text { AD } \\
(n=9,161)\end{array}$ & $\begin{array}{l}\text { Unadjusted } \\
\text { OR }(95 \% \mathrm{Cl})\end{array}$ & $P$ value $^{\mathrm{a}}$ & $\begin{array}{c}\text { Adjusted } \\
\text { OR }(95 \% \mathrm{Cl})\end{array}$ & $P$ value ${ }^{b}$ \\
\hline I & A00 to B99 & Certain infectious and parasitic diseases & $87(13.7)$ & $1,064(11.6)$ & $1.21(0.96$ to 1.53$)$ & 0.111 & 1.25 (0.98 to 1.59$)$ & 0.069 \\
\hline$\|$ & C00 to D48 & Neoplasms & $203(32.0)$ & $2,733(29.8)$ & 1.11 (0.93 to 1.32$)$ & 0.245 & $1.06(0.88$ to 1.27$)$ & 0.541 \\
\hline III & D50 to D89 & $\begin{array}{l}\text { Diseases of the blood and blood-forming } \\
\text { organs and certain disorders involving } \\
\text { the immune mechanism }\end{array}$ & $29(4.6)$ & $433(4.7)$ & 0.97 (0.66 to 1.42$)$ & 0.861 & 1.01 (0.68 to 1.49$)$ & 0.976 \\
\hline IV & E00 to E90 & Endocrine, nutritional and metabolic diseases & $79(12.5)$ & $1,088(11.9)$ & $1.06(0.83$ to 1.35$)$ & 0.661 & 1.16 (0.90 to 1.49$)$ & 0.239 \\
\hline V & F00 to F99 & Mental and behavioral disorders & $419(66.1)$ & $3,543(38.7)$ & 3.09 (2.61 to 3.66$)$ & $<0.001$ & $3.14(2.63$ to 3.75$)$ & $<0.001$ \\
\hline $\mathrm{VI}$ & G00 to G99 & Diseases of the nervous system & $558(88.0)$ & $6,508(71.0)$ & 2.99 (2.34 to 3.82$)$ & $<0.001$ & $2.78(2.15$ to 3.58$)$ & $<0.001$ \\
\hline VII & H0O to H59 & Diseases of the eye and adnexa & $367(57.9)$ & $4,390(47.9)$ & 1.49 (1.27 to 1.76$)$ & $<0.001$ & 1.69 (1.42 to 2.01$)$ & $<0.001$ \\
\hline VIII & $\mathrm{H} 60$ to H95 & Diseases of the ear and mastoid process & $96(15.1)$ & $1,462(16.0)$ & 0.94 (0.75 to 1.18$)$ & 0.586 & 0.97 (0.77 to 1.22$)$ & 0.810 \\
\hline IX & 100 to 199 & Diseases of the circulatory system & $293(46.2)$ & $3,693(40.3)$ & 1.27 (1.08 to 1.49$)$ & 0.003 & 1.29 (1.08 to 1.52$)$ & 0.004 \\
\hline$x$ & J00 to 199 & Diseases of the respiratory system & $146(23.0)$ & $1,663(18.2)$ & 1.35 (1.11 to 1.63$)$ & 0.002 & $1.30(1.06$ to 1.59$)$ & 0.010 \\
\hline$X I$ & K00 to K93 & Diseases of the digestive system & $237(37.4)$ & $2,966(32.4)$ & 1.25 (1.05 to 1.47$)$ & 0.009 & 1.17 (0.98 to 1.39$)$ & 0.082 \\
\hline XII & L00 to L99 & $\begin{array}{l}\text { Diseases of the skin and subcutaneous } \\
\text { tissue }\end{array}$ & $155(24.4)$ & $1,918(20.9)$ & 1.22 (1.01 to 1.47$)$ & 0.036 & 1.27 (1.05 to 1.54$)$ & 0.016 \\
\hline$X I I I$ & M00 to M99 & $\begin{array}{l}\text { Diseases of the musculoskeletal system } \\
\text { and connective tissue }\end{array}$ & $273(43.1)$ & $3,732(40.7)$ & $1.10(0.93$ to 1.29$)$ & 0.250 & $1.19(1.01$ to 1.41$)$ & 0.040 \\
\hline XIV & N00 to N99 & Diseases of the genitourinary system & $233(36.8)$ & $2,984(32.6)$ & 1.20 (1.02 to 1.42$)$ & 0.030 & 1.24 (1.04 to 1.47$)$ & 0.015 \\
\hline$X V$ & O00 to O99 & Pregnancy, childbirth and the puerperium & $1(0.2)$ & $2(0.0)$ & - & - & - & - \\
\hline$X V I$ & P00 to P96 & $\begin{array}{l}\text { Certain conditions originating in the } \\
\text { perinatal period }\end{array}$ & 0 & 0 & - & - & - & - \\
\hline$X V I I$ & Q00 to Q99 & $\begin{array}{l}\text { Congenital malformations, deformations } \\
\text { and chromosomal abnormalities }\end{array}$ & $5(0.8)$ & $57(0.6)$ & 1.27 (0.51 to 3.18$)$ & 0.609 & 1.55 (0.61 to 3.98$)$ & 0.358 \\
\hline$X V I I I$ & R00 to R99 & $\begin{array}{l}\text { Symptoms, signs and abnormal clinical } \\
\text { and laboratory findings, not elsewhere } \\
\text { classified }\end{array}$ & $460(72.6)$ & $5,896(64.4)$ & $1.46(1.22$ to 1.75$)$ & $<0.001$ & 1.44 (1.19 to 1.73$)$ & $<0.001$ \\
\hline XIX & S00 to T98 & $\begin{array}{l}\text { Injury, poisoning and certain other } \\
\text { consequences of external causes }\end{array}$ & $369(58.2)$ & $4,679(51.1)$ & 1.33 (1.13 to 1.57$)$ & 0.001 & 1.54 (1.30 to 1.83$)$ & $<0.001$ \\
\hline$X X$ & V01 to Y98 & $\begin{array}{l}\text { External causes of morbidity and } \\
\text { mortality }\end{array}$ & 0 & $1(0.0)$ & - & - & - & - \\
\hline$X X \mid$ & Z00 to Z99 & $\begin{array}{l}\text { Factors influencing health status and } \\
\text { contact with health services }\end{array}$ & $523(82.5)$ & $6,718(73.3)$ & 1.71 (1.39 to 2.11 ) & $<0.001$ & 1.73 (1.39 to 2.16$)$ & $<0.001$ \\
\hline
\end{tabular}

Adjustment is made for age, sex, and Mini-Mental State Examination score. The AD group is considered the reference group. Statistically significant ORs ( $P<0.05)$ in bold. $A D$, Alzheimer's disease; $\mathrm{Cl}$, confidence interval;

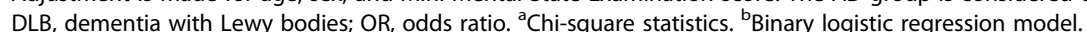


Table 3 Comorbidity profile of patients with dementia with Lewy bodies $(n=634)$ versus Alzheimer's disease patients $(n=9,161)$ within different subgroups regarding gender, cognitive level at the time of diagnosis and living place using the chapters of the International Statistical Classification of Diseases and Related Health Problems, 10th Revision

\begin{tabular}{|c|c|c|c|c|c|c|c|c|c|c|c|c|}
\hline Title & Gender & $\begin{array}{l}\text { DLB } \\
(\%)\end{array}$ & $\begin{array}{l}A D \\
(\%)\end{array}$ & $P$ value & Cognition & $\begin{array}{l}\text { DLB } \\
(\%)\end{array}$ & $\begin{array}{l}A D \\
(\%)\end{array}$ & $P$ value & Living place & $\begin{array}{l}\text { DLB } \\
(\%)\end{array}$ & $\begin{array}{l}A D \\
(\%)\end{array}$ & $P$ value \\
\hline \multirow{2}{*}{$\begin{array}{l}\text { Certain infectious and } \\
\text { parasitic diseases }\end{array}$} & Male & 14.9 & 12.5 & 0.183 & MMSE $\geq 22$ & 16.3 & 11.2 & 0.005 & Own house & 14.3 & 11.4 & 0.038 \\
\hline & Female & 11.9 & 11.1 & 0.703 & MMSE $<22$ & 11.9 & 12.2 & 0.855 & Nursing home & 9.3 & 15.0 & 0.188 \\
\hline \multirow{2}{*}{ Neoplasms } & Male & 35.6 & 33.8 & 0.494 & MMSE $\geq 22$ & 32.8 & 31.6 & 0.652 & Own house & 32.4 & 30.1 & 0.259 \\
\hline & Female & 26.6 & 27.7 & 0.701 & MMSE $<22$ & 31.9 & 27.9 & 0.169 & Nursing home & 29.3 & 25.4 & 0.467 \\
\hline \multirow{2}{*}{$\begin{array}{l}\text { Diseases of the blood and } \\
\text { blood-forming organs and } \\
\text { certain disorders involving } \\
\text { the immune mechanism }\end{array}$} & Male & 5.2 & 4.8 & 0.687 & MMSE $\geq 22$ & 3.6 & 4.5 & 0.447 & Own house & 4.7 & 4.6 & 0.967 \\
\hline & Female & 3.6 & 4.7 & 0.403 & MMSE $<22$ & 5.9 & 4.8 & 0.414 & Nursing home & 4.0 & 6.8 & 0.457 \\
\hline \multirow{2}{*}{$\begin{array}{l}\text { Endocrine, nutritional and } \\
\text { metabolic diseases }\end{array}$} & Male & 12.8 & 10.9 & 0.262 & MMSE $\geq 22$ & 10.5 & 11.7 & 0.526 & Own house & 12.3 & 11.8 & 0.700 \\
\hline & Female & 11.9 & 12.4 & 0.819 & MMSE $<22$ & 15.9 & 11.8 & 0.046 & Nursing home & 13.3 & 13.5 & 0.973 \\
\hline \multirow{2}{*}{$\begin{array}{l}\text { Mental and behavioral } \\
\text { disorders }\end{array}$} & Male & 67.3 & 37.4 & $<0.001$ & MMSE $\geq 22$ & 65.7 & 40.8 & $<0.001$ & Own house & 65.5 & 38.8 & $<0.001$ \\
\hline & Female & 64.3 & 39.3 & $<0.001$ & MMSE $<22$ & 66.7 & 36.0 & $<0.001$ & Nursing home & 70.7 & 36.5 & $<0.001$ \\
\hline \multirow{2}{*}{$\begin{array}{l}\text { Diseases of the nervous } \\
\text { system }\end{array}$} & Male & 91.4 & 72.8 & $<0.001$ & MMSE $\geq 22$ & 89.5 & 75.5 & $<0.001$ & Own house & 88.7 & 72.2 & $<0.001$ \\
\hline & Female & 82.9 & 70.1 & $<0.001$ & MMSE $<22$ & 86.3 & 66.8 & $<0.001$ & Nursing home & 82.7 & 52.3 & $<0.001$ \\
\hline \multirow{2}{*}{$\begin{array}{l}\text { Diseases of the eye and } \\
\text { adnexa }\end{array}$} & Male & 56.5 & 44.2 & $<0.001$ & MMSE $\geq 22$ & 60.2 & 49.0 & $<0.001$ & Own house & 58.3 & 47.7 & $<0.001$ \\
\hline & Female & 59.9 & 49.9 & 0.002 & MMSE $<22$ & 55.6 & 47.0 & 0.007 & Nursing home & 54.7 & 52.0 & 0.660 \\
\hline \multirow{2}{*}{$\begin{array}{l}\text { Diseases of the ear and } \\
\text { mastoid process }\end{array}$} & Male & 15.4 & 17.2 & 0.383 & MMSE $\geq 22$ & 17.5 & 17.1 & 0.857 & Own house & 15.7 & 16.2 & 0.790 \\
\hline & Female & 14.7 & 15.3 & 0.794 & MMSE $<22$ & 14.1 & 14.6 & 0.819 & Nursing home & 10.7 & 12.9 & 0.588 \\
\hline \multirow{2}{*}{$\begin{array}{l}\text { Diseases of the circulatory } \\
\text { system }\end{array}$} & Male & 45.8 & 43.5 & 0.391 & MMSE $\geq 22$ & 43.7 & 40.8 & 0.296 & Own house & 46.3 & 40.2 & 0.005 \\
\hline & Female & 46.8 & 38.6 & 0.009 & MMSE $<22$ & 49.6 & 39.1 & 0.001 & Nursing home & 45.3 & 41.2 & 0.499 \\
\hline \multirow{2}{*}{$\begin{array}{l}\text { Diseases of the respiratory } \\
\text { system }\end{array}$} & Male & 27.7 & 20.5 & 0.001 & MMSE $\geq 22$ & 22.0 & 17.6 & 0.043 & Own house & 22.9 & 18.0 & 0.004 \\
\hline & Fem & 15.9 & 16.9 & 0. & MMSE $<22$ & 24.4 & 18.6 & 0 & Nurs & 24.0 & 20.1 & 0.438 \\
\hline \multirow{2}{*}{$\begin{array}{l}\text { Diseases of the digestive } \\
\text { system }\end{array}$} & Male & 41.6 & 37.0 & 0.079 & MMSE $\geq 22$ & 36.7 & 34.3 & 0.357 & Own house & 37.7 & 32.7 & 0.013 \\
\hline & Female & 31.0 & 29.9 & 0.721 & MMSE $<22$ & 38.9 & 30.3 & 0.003 & Nursing home & 34.7 & 27.9 & 0.229 \\
\hline \multirow{2}{*}{$\begin{array}{l}\text { Diseases of the skin and } \\
\text { subcutaneous tissue }\end{array}$} & Male & 24.3 & 20.2 & 0.057 & MMSE $\geq 22$ & 25.3 & 22.5 & 0.230 & Own house & 24.7 & 21.1 & 0.043 \\
\hline & Female & 24.6 & 21.3 & 0.217 & MMSE $<22$ & 24.1 & 19.3 & 0.056 & Nursing home & 22.7 & 18.6 & 0.397 \\
\hline \multirow{2}{*}{$\begin{array}{l}\text { Diseases of the musculoskeletal } \\
\text { system and connective tissue }\end{array}$} & Male & 39.8 & 36.1 & 0.157 & MMSE $\geq 22$ & 41.3 & 42.9 & 0.555 & Own house & 42.9 & 41.0 & 0.371 \\
\hline & Female & 48.0 & 43.2 & 0.132 & MMSE $<22$ & 45.6 & 38.5 & 0.022 & Nursing home & 44.0 & 37.5 & 0.280 \\
\hline \multirow{2}{*}{$\begin{array}{l}\text { Diseases of the genitourinary } \\
\text { system }\end{array}$} & Male & 36.4 & 32.1 & 0.093 & MMSE $\geq 22$ & 38.0 & 33.6 & 0.108 & Own house & 38.3 & 32.6 & 0.005 \\
\hline & Female & 37.3 & 32.8 & 0.138 & MMSE $<22$ & 35.6 & 31.1 & 0.132 & Nursing home & 25.3 & 32.6 & 0.205 \\
\hline \multirow{2}{*}{$\begin{array}{l}\text { Pregnancy, childbirth and } \\
\text { the puerperium }\end{array}$} & Male & - & - & - & MMSE $\geq 22$ & 0.3 & 0 & 0.062 & Own house & 0.2 & 0 & 0.061 \\
\hline & Female & 0.4 & 0 & 0.117 & MMSE $<22$ & 0 & 0.1 & 1 & Nursing home & 0 & 0.4 & 1 \\
\hline \multirow{2}{*}{$\begin{array}{l}\text { Certain conditions originating } \\
\text { in the perinatal period }\end{array}$} & Male & 0 & 0 & - & MMSE $\geq 22$ & 0 & 0 & - & Own house & 0 & 0 & - \\
\hline & Female & 0 & 0 & - & MMSE $<22$ & 0 & 0 & - & Nursing home & 0 & 0 & - \\
\hline \multirow{2}{*}{$\begin{array}{l}\text { Congenital malformations, } \\
\text { deformations and chromosomal } \\
\text { abnormalities }\end{array}$} & Male & 1.0 & 0.6 & 0.300 & MMSE $\geq 22$ & 0.9 & 0.6 & 0.464 & Own house & 0.7 & 0.5 & 0.545 \\
\hline & Female & 0.4 & 0.6 & 1 & MMSE $<22$ & 0.7 & 0.4 & 0.349 & Nursing home & 1.3 & 2.1 & 1 \\
\hline \multirow{2}{*}{$\begin{array}{l}\text { Symptoms, signs and abnormal } \\
\text { clinical and laboratory findings, } \\
\text { not elsewhere classified }\end{array}$} & Male & 72.8 & 66.9 & 0.020 & MMSE $\geq 22$ & 74.1 & 67.2 & 0.010 & Own house & 72.3 & 64.5 & $<0.001$ \\
\hline & Female & 72.2 & 63.0 & 0.003 & MMSE $<22$ & 71.5 & 61.3 & 0.001 & Nursing home & 74.7 & 62.7 & 0.043 \\
\hline \multirow{2}{*}{$\begin{array}{l}\text { Injury, poisoning and certain } \\
\text { other consequences of } \\
\text { external causes }\end{array}$} & Male & 50.8 & 45.1 & 0.034 & MMSE $\geq 22$ & 59.6 & 49.2 & $<0.001$ & Own house & 58.3 & 50.2 & $<0.001$ \\
\hline & Female & 69.4 & 54.3 & $<0.001$ & MMSE $<22$ & 56.7 & 53.5 & 0.312 & Nursing home & 57.3 & 64.8 & 0.206 \\
\hline
\end{tabular}


Table 3 Comorbidity profile of patients with dementia with Lewy bodies $(n=634)$ versus Alzheimer's disease patients $(n=9,161)$ within different subgroups regarding gender, cognitive level at the time of diagnosis and living place using the chapters of the International Statistical Classification of Diseases and Related Health Problems, 10th Revision (Continued)

\begin{tabular}{|c|c|c|c|c|c|c|c|c|c|c|c|c|}
\hline \multirow{2}{*}{$\begin{array}{l}\text { External causes of morbidity } \\
\text { and mortality }\end{array}$} & Male & 0 & 0 & - & MMSE $\geq 22$ & 0 & 0 & - & Own house & 0 & 0 & - \\
\hline & Female & 0 & 0 & - & MMSE < 22 & 0 & 0 & - & Nursing home & 0 & 0 & - \\
\hline \multirow{2}{*}{$\begin{array}{l}\text { Factors influencing health } \\
\text { status and contact with } \\
\text { health services }\end{array}$} & Male & 81.4 & 73.0 & $<0.001$ & MMSE $\geq 22$ & 84.3 & 76.8 & 0.001 & Own house & 83.2 & 73.8 & $<0.00$ \\
\hline & Female & 84.1 & 73.5 & $<0.001$ & MMSE $<22$ & 81.1 & 69.8 & $<0.001$ & Nursing home & 77.3 & 65.8 & 0.047 \\
\hline
\end{tabular}

Statistically significant differences $(P<0.05)$ in bold. Univariate comparisons were performed using either the chi-square or Fisher's exact test wherever appropriate. $A D$, Alzheimer's disease; DLB, dementia with Lewy bodies; MMSE, Mini-Mental State Examination.

of the ICD version 10 codes are presented in Table 4 . Cerebrovascular diseases were more common in the DLB group after adjustment for age and sex $(16.2 \%$ vs. $10.0 \%$, adjusted $\mathrm{OR}=1.74(95 \% \mathrm{CI}=1.38$ to 2.19$)$ ). As illustrated in Figure 1, 12.7\% of the AD patients had a zero score according to the Charlson scoring of the comorbidities, while only $3.3 \%$ of the DLB patients showed this condition. The proportion of individuals with one, two and three or more comorbidity categories of Charlson scoring was higher in the DLB group $(P<0.001)$. Moreover, DLB patients had a significantly higher mean for the total Charlson score (1.52 $(\mathrm{SD}=0.85)$ vs. $1.33(\mathrm{SD}=0.89))$. This difference remained significant even after multivariate adjustment $(\mathrm{OR}=1.22(95 \%$ $\mathrm{CI}=1.12$ to 1.33$)$ ).

\section{Neuropsychiatric comorbidities}

Considering the date of registration in SveDem and the Swedish National Patient Registry, occurrence of the selected neuropsychiatric comorbidities was determined as either before or after dementia diagnosis. As presented in Table 5, depression was the most common neuropsychiatric comorbidity before the diagnosis of dementia in both groups (6.0\% in DLB and $3.0 \%$ in AD). Among strokes, cerebral infarction was more common in the DLB group than in the $\mathrm{AD}$ group, while the frequency of cerebral hemorrhages did not differ between the AD and DLB groups. According to univariate comparisons (Table 5), depression $(P<0.001)$, behavioral disorders $(P=0.012)$, stroke $(P=0.002)$ and migraine $(P=0.028)$ were all more frequent in individuals with DLB compared with the $\mathrm{AD}$

Table 4 Comorbidity profile of the patients with dementia with Lewy bodies versus Alzheimer's disease patients based on the Royal College of Surgeons Charlson Score indicating International Classification of Disease, 10th revision codes for 14 disease categories

\begin{tabular}{|c|c|c|c|c|c|c|}
\hline Disease category & $\begin{array}{c}\text { DLB } \\
(n=634)\end{array}$ & $\begin{array}{c}A D \\
(n=9,161)\end{array}$ & $\begin{array}{l}\text { Unadjusted } \\
\text { OR (95\% Cl) }\end{array}$ & $P$ value $^{\mathrm{a}}$ & $\begin{array}{c}\text { Adjusted } \\
\text { OR }(95 \% \mathrm{Cl})\end{array}$ & $P$ value ${ }^{b}$ \\
\hline Myocardial infarction & $34(5.4)$ & $532(5.8)$ & 0.92 (0.64 to 1.31$)$ & 0.643 & 0.85 (0.59 to 1.22$)$ & 0.372 \\
\hline Congestive cardiac failure & $38(6.0)$ & $458(5.0)$ & 1.21 (0.86 to 1.70$)$ & 0.270 & 1.21 (0.85 to 1.73$)$ & 0.282 \\
\hline Peripheral vascular disease & $15(2.4)$ & $271(3.0)$ & 0.79 (0.47 to 1.34$)$ & 0.392 & 0.77 (0.45 to 1.31$)$ & 0.335 \\
\hline Cerebrovascular disease & $103(16.2)$ & $912(10.0)$ & 1.75 (1.40 to 2.19 ) & $<0.001$ & 1.74 (1.38 to 2.19 ) & $<0.001$ \\
\hline Chronic pulmonary disease & $27(4.3)$ & $480(5.2)$ & $0.80(0.54$ to 1.20$)$ & 0.281 & 0.88 (0.59 to 1.31$)$ & 0.525 \\
\hline Rheumatological disease & $12(1.9)$ & $286(3.1)$ & 0.60 (0.33 to 1.07$)$ & 0.081 & 0.64 (0.35 to 1.19$)$ & 0.160 \\
\hline Liver disease & $4(0.6)$ & $48(0.5)$ & $1.20(0.43$ to 3.35$)$ & 0.578 & 1.13 (0.40 to 3.19$)$ & 0.818 \\
\hline Diabetes mellitus & $26(4.1)$ & $481(5.3)$ & 0.77 (0.52 to 1.15$)$ & 0.206 & 0.73 (0.48 to 1.11$)$ & 0.145 \\
\hline Hemiplegia or paraplegia & 0 & $19(0.2)$ & - & 0.631 & - & 0.998 \\
\hline Renal disease & $11(1.7)$ & $98(1.1)$ & 1.63 (0.87 to 3.06$)$ & 0.123 & 1.57 (0.83 to 2.97$)$ & 0.167 \\
\hline Any malignancy & $94(14.8)$ & $1283(14.0)$ & 1.07 (0.85 to 1.34$)$ & 0.565 & $0.96(0.75$ to 1.21$)$ & 0.707 \\
\hline Metastatic solid tumor & $2(0.3)$ & $74(0.8)$ & 0.39 (0.09 to 1.59$)$ & 0.239 & 0.42 (0.10 to 1.74$)$ & 0.235 \\
\hline AIDS/HIV infection & 0 & $1(0.0)$ & - & - & - & - \\
\hline Total Charlson score & $1.52(0.85)$ & $1.33(0.89)$ & 1.25 (1.15 to 1.36$)$ & $<0.001$ & $1.22(1.12$ to 1.33$)$ & $<0.001$ \\
\hline
\end{tabular}

Data presented as mean (standard deviation). Adjustment is made for age, sex, and Mini-Mental State Examination score. The AD group is considered the reference group. The dementia category of the original Charlson scoring is not reported here because the whole study population is dementia patients in our study. Statistically significant ORs $(P<0.05)$ in bold. AD, Alzheimer's disease; $\mathrm{Cl}$, confidence interval; DLB, dementia with Lewy bodies; OR, odds ratio. ${ }^{\mathrm{a}} \mathrm{Chi}$-square statistics. ${ }^{\mathrm{b}}$ Binary logistic regression model. 


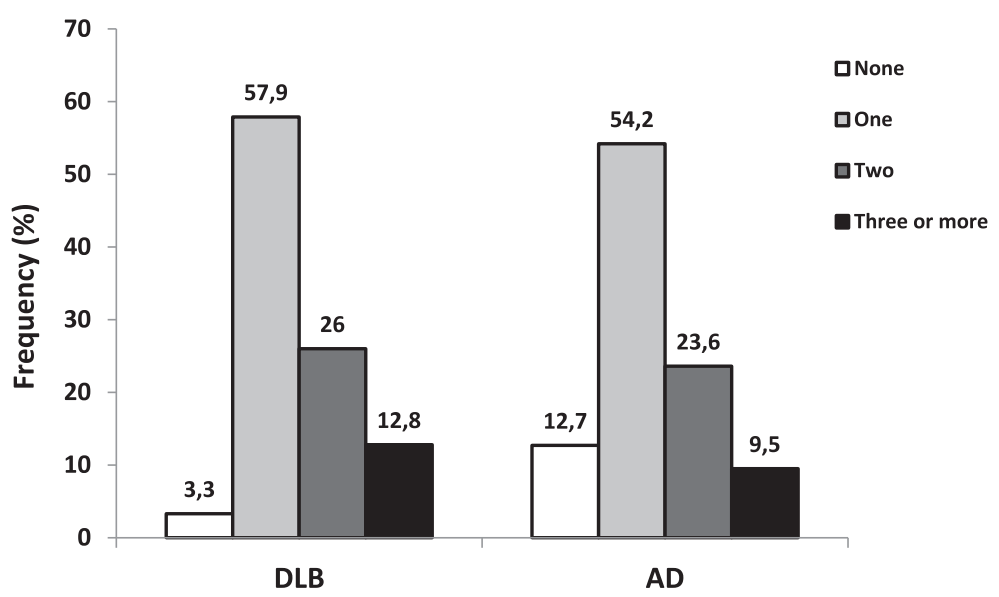

Figure 1 Frequency of dementia with Lewy bodies and Alzheimer's disease in patients with different number of comorbidities. Frequency of dementia with Lewy bodies (DLB, $n=634)$ and Alzheimer's disease $(A D, n=9,161)$ in patients with different number of comorbidities based on the categories of the Royal College of Surgeons Charlson Score identified on the International Classification of Disease, 10th revision codes.

group. However, the other types of headache were not significantly different between the two groups $(3.2 \%$ in $\mathrm{DLB}$ and $3.4 \%$ in $\mathrm{AD}, \mathrm{OR}=0.92(95 \% \mathrm{CI}=0.58$ to 1.45$)$, $P=0.713)$.

Figure 2 illustrates the forest plots of adjusted OR for each neuropsychiatric comorbidity in DLB with AD as the reference group. With respect to the timing of the events, depression (adjusted OR $=2.12(95 \% \mathrm{CI}=1.49$ to 3.03)) and migraine (adjusted OR $=3.65$ (95\% CI $=1.48$ to 9.0$)$ ) were more commonly recorded before the diagnosis of dementia in the DLB group (Figure 2B). As shown in Figure 2C, ischemic stroke (adjusted $\mathrm{OR}=1.89$ ( $95 \% \mathrm{CI}=1.21$ to 2.96$)$ ) was the only significant comorbid condition that was more likely to happen among the DLB patients compared with the $\mathrm{AD}$ population after the onset of dementia.

Further subgroup analysis was performed regarding gender, cognitive level and living place. As summarized in Table 6, depression and stroke were more common in the DLB group compared with AD patients among both males and females (all $P<0.05$ ), whereas the higher prevalence of anxiety in DLB patients was statistically significant only among the males $(3.4 \%$ vs. $1.8 \%, P=0.031)$. With respect to level of cognition, depression, stroke and migraine were significantly more common in DLB patients compared with the $\mathrm{AD}$ group only among those with MMSE $<22$ (all $P<0.05$ ). Depression, sleep disorders and stroke were more commonly occurred in the DLB patients compared with the $\mathrm{AD}$ group among those who were living in their own house (all $P<0.05$ ), while migraine was more prevalent in DLB patients who lived in nursing homes $(2.7 \%$ vs. $0.2 \%, P=0.045)$.

\section{Discussion}

In this study we investigated selected risk factors and comorbidities in patients suffering from DLB in comparison with $\mathrm{AD}$. There were more males in the DLB group, which is in line with previous studies [21]. At the time when dementia diagnosis was set, DLB patients were younger, and, despite similar level of cognitive impairment, lived more frequently in nursing homes and received more psychiatric medication and a higher total number of drugs. This indicates a worse health profile at the time when dementia was diagnosed and suggests that DLB patients may have been affected by a larger number of diseases before they developed dementia compared with the AD subjects. Patients with DLB were more frequently affected with depression, stroke and cerebrovascular infarctions and migraine.

\section{Medication}

There were some interesting differences in the use of medication. Cholinesterase inhibitors were used in the majority of DLB and AD patients. Although these drugs are indicated for AD and Parkinson's disease with dementia, but not formally for DLB, there is good evidence that they are also useful in DLB [22,23]. Memantine was prescribed for $15 \%$ of DLB patients and $10 \%$ of AD patients, although the evidence is less conclusive for DLB. However, there are some indications that memantine may in fact be useful also for DLB [24], including meta-analysis data [23].

\section{Depression}

Depression was more frequent in both men and women in the DLB group compared with $\mathrm{AD}$, particularly in 
Table 5 Occurrence and timing for different neuropsychiatric comorbidities in patients with dementia with Lewy bodies versus Alzheimer's disease patients

\begin{tabular}{|c|c|c|c|}
\hline Comorbidity & $\begin{array}{l}\text { Dementia with Lewy bodies } \\
\qquad(n=634)\end{array}$ & $\begin{array}{l}\text { Alzheimer's disease } \\
\qquad(n=9,161)\end{array}$ & $P$ value $^{\mathrm{a}}$ \\
\hline Depression & & & $<0.001$ \\
\hline None & $587(92.7)$ & $8,736(95.5)$ & \\
\hline Before dementia diagnosis & $38(6.0)$ & $277(3.0)$ & \\
\hline After dementia diagnosis & $8(1.3)$ & $130(1.4)$ & \\
\hline Anxiety & & & 0.508 \\
\hline None & $612(96.7)$ & $8,905(97.4)$ & \\
\hline Before dementia diagnosis & $16(2.5)$ & $172(1.9)$ & \\
\hline After dementia diagnosis & $5(0.8)$ & $66(0.7)$ & \\
\hline Behavioral disorders & & & 0.012 \\
\hline None & $612(96.7)$ & $8,964(98.0)$ & \\
\hline Before dementia diagnosis & $9(1.4)$ & $107(1.2)$ & \\
\hline After dementia diagnosis & $12(1.9)$ & $72(0.8)$ & \\
\hline Bipolar affective disorder & & & 0.258 \\
\hline None & $628(99.2)$ & $9,100(99.5)$ & \\
\hline Before dementia diagnosis & $5(0.8)$ & $36(0.4)$ & \\
\hline After dementia diagnosis & 0 & $7(0.1)$ & \\
\hline Sleep disorders & & & 0.093 \\
\hline None & $616(97.3)$ & $9,001(98.4)$ & \\
\hline Before dementia diagnosis & $14(2.2)$ & $116(1.3)$ & \\
\hline After dementia diagnosis & $3(0.5)$ & $26(0.3)$ & \\
\hline Syncope & & & 0.472 \\
\hline None & $587(92.7)$ & $8,486(92.8)$ & \\
\hline Before dementia diagnosis & $35(5.5)$ & $443(4.8)$ & \\
\hline After dementia diagnosis & $11(1.7)$ & $214(2.3)$ & \\
\hline Stroke & & & 0.002 \\
\hline None & $580(91.6)$ & $8,665(94.8)$ & \\
\hline Before dementia diagnosis & $28(4.4)$ & $277(3.0)$ & \\
\hline After dementia diagnosis & $25(3.9)$ & $201(2.2)$ & \\
\hline Cerebral hemorrhage & & & 0.709 \\
\hline None & $623(98.4)$ & $9,015(98.6)$ & \\
\hline Before dementia diagnosis & $6(0.9)$ & $62(0.7)$ & \\
\hline After dementia diagnosis & $4(0.6)$ & $66(0.7)$ & \\
\hline Epilepsy & & & 0.291 \\
\hline None & $622(98.3)$ & $9,022(98.7)$ & \\
\hline Before dementia diagnosis & $8(1.3)$ & $66(0.7)$ & \\
\hline After dementia diagnosis & $3(0.4)$ & $55(0.6)$ & \\
\hline Migraine & & & 0.028 \\
\hline None & $627(99.1)$ & $9,113(99.7)$ & \\
\hline Before dementia diagnosis & $6(0.9)$ & $28(0.3)$ & \\
\hline After dementia diagnosis & 0 & $2(0.0)$ & \\
\hline
\end{tabular}

Data presented as number (\%). Statistically significant differences $(P<0.05)$ in bold. ${ }^{\text {P}}$ Pearson chi-square statistics. 


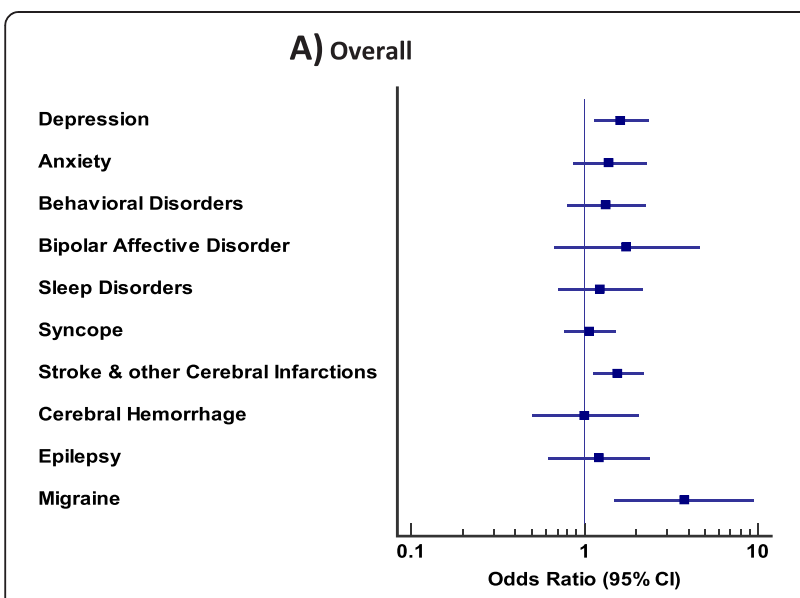

B) Before Dementia Diagnosis

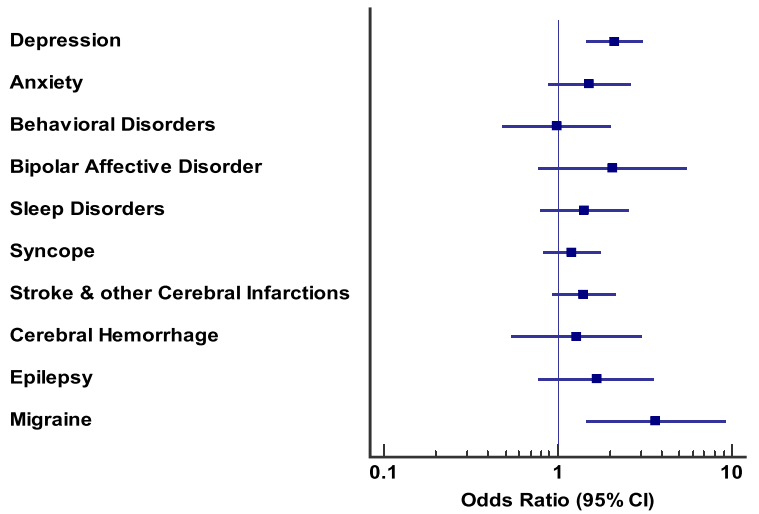

C) After Dementia Diagnosis

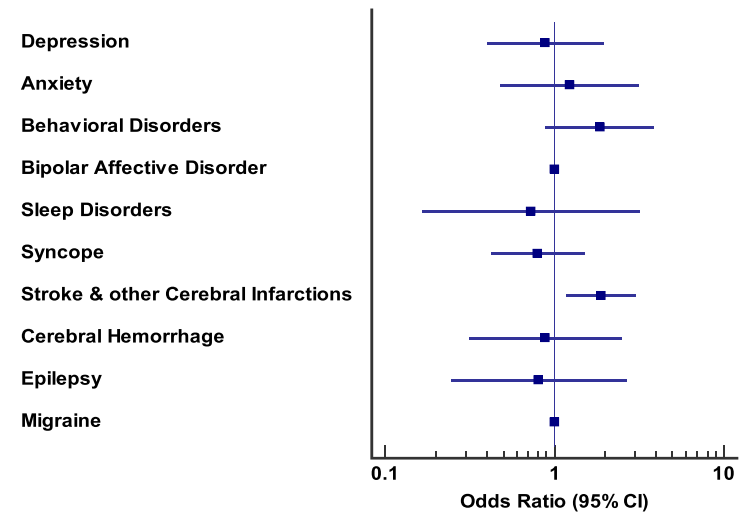

Figure 2 Forest plot for odds ratios of the selected list of neuropsychiatric comorbidities for dementia with Lewy bodies compared with Alzheimer's disease as the reference group in different three conditions. (A) Overall assessment (regardless of the timing). (B) Comorbidities recorded prior to the diagnosis of dementia as a risk factor for type of dementia (DLB vs. AD). (C) Type of dementia (DLB vs. AD) as a risk factor for comorbidities occurred after the diagnosis of dementia. AD, Alzheimer's disease; $\mathrm{Cl}$, confidence interval; DLB, dementia with Lewy bodies. patients with a lower cognitive status at the time when dementia was diagnosed. Depression is a common feature of DLB [11], especially in its early stages. Several hypotheses have linked depression to the etiology and pathophysiology of dementia, depression may be a risk factor for DLB [9]. DLB has also been associated with a higher risk of depression [25]. The etiology of depression is probably multifactorial and the relation to dementia is complex. In our study, depression was significantly more often diagnosed in DLB patients before they were diagnosed with dementia. After the dementia diagnosis was set, depression occurrence did not differ between the DLB and $\mathrm{AD}$ patients.

It is a matter of dispute whether depression is a risk factor or a prodromal stage of DLB. Nonmotor symptoms and widespread brain pathological changes are believed to occur in DLB before dementia onset [26], so depression may be a sign of underlying pathological changes that are already present in DLB subjects. It would be of interest to investigate whether prevention or treatment of depression could decrease the incidence of DLB or postpone the development of dementia.

\section{Migraine}

In our study, migraine was more common in the DLB group before dementia was diagnosed. Furthermore, it occurred more frequently in DLB patients that had a lower MMSE score at the time of diagnosis. Migraine was shown as a risk factor for developing dementia [27] and associated with smaller brain tissue volumes [28]. Recently, headache has been suggested as a risk factor for the development of vascular dementia in a prospective populationbased study [29]. However, there are no previous studies investigating migraine in DLB patients. Conditions that are common in DLB patients and subjects suffering from migraine include complex visual hallucination [30] and disorders in olfactory perception [31]. Even though their etiology seems different, further research on these two disorders could provide valuable insights into the relationship between DLB and migraine.

\section{Stroke}

Strokes were found to be more common for both men and women in the DLB group compared with the AD group, especially in subjects with lower MMSE scores. The occurrence of cerebrovascular infarctions but not cerebral hemorrhages after dementia diagnosis was significantly higher in the DLB group compared with AD patients. This relationship was not significant before dementia was diagnosed. This finding is surprising as strokes are common predictors for AD [32]. The difference in use of antipsychotics may be an explanation.

Studies on cerebrovascular pathology in DLB patients are not numerous and provide contradictory results. In a 
Table 6 Frequency of different neuropsychiatric comorbidities in patients with dementia with Lewy bodies $(n=634)$ versus Alzheimer's disease patients $(n=9,161)$ within different subgroups regarding gender, cognitive level at the time of diagnosis and living place using the chapters of the International Statistical Classification of Diseases and Related Health Problems, 10th Revision

\begin{tabular}{|c|c|c|c|c|c|c|c|c|c|c|c|c|}
\hline Title & Gender & DLB (\%) & $A D(\%)$ & $P$ value & Cognition & DLB (\%) & AD (\%) & $P$ value & Living place & DLB (\%) & $A D(\%)$ & $P$ value \\
\hline \multirow{2}{*}{ Depression } & Male & 6.3 & 3.8 & 0.020 & MMSE $\geq 22$ & 6.3 & 5.2 & 0.350 & Own house & 7.0 & 4.5 & 0.006 \\
\hline & Female & 8.7 & 4.8 & 0.005 & MMSE $<22$ & 7.4 & 3.5 & 0.001 & Nursing home & 9.3 & 3.9 & 0.068 \\
\hline \multirow{2}{*}{ Anxiety } & Male & 3.4 & 1.8 & 0.031 & MMSE $\geq 22$ & 3.3 & 2.7 & 0.464 & Own house & 3.2 & 2.6 & 0.372 \\
\hline & Female & 3.2 & 3.0 & 0.901 & MMSE $<22$ & 3.3 & 2.7 & 0.528 & Nursing home & 4.0 & 2.8 & 0.469 \\
\hline \multirow{2}{*}{ Behavioral disorders } & Male & 3.4 & 2.6 & 0.381 & MMSE $\geq 22$ & 2.4 & 1.9 & 0.471 & Own house & 2.9 & 1.8 & 0.079 \\
\hline & Female & 3.2 & 1.6 & 0.071 & MMSE $<22$ & 3.7 & 2.0 & 0.062 & Nursing home & 6.7 & 4.1 & 0.362 \\
\hline \multirow{2}{*}{$\begin{array}{l}\text { Bipolar affective } \\
\text { disorders }\end{array}$} & Male & 0.5 & 0.5 & 0.702 & MMSE $\geq 22$ & 0.6 & 0.5 & 0.689 & Own house & 0.9 & 0.4 & 0.185 \\
\hline & Female & 1.2 & 0.5 & 0.129 & MMSE $<22$ & 1.1 & 0.4 & 0.105 & Nursing home & 0 & 1.0 & 1 \\
\hline \multirow{2}{*}{ Sleep disorders } & Male & 3.9 & 2.5 & 0.094 & MMSE $\geq 22$ & 2.7 & 2.0 & 0.339 & Own house & 2.7 & 1.6 & 0.040 \\
\hline & Female & 0.8 & 1.1 & 1 & MMSE $<22$ & 2.2 & 1.1 & 0.124 & Nursing home & 2.7 & 1.4 & 0.325 \\
\hline \multirow{2}{*}{ Syncope } & Male & 7.1 & 6.7 & 0.789 & MMSE $\geq 22$ & 6.9 & 7.4 & 0.782 & Own house & 7.5 & 7.2 & 0.740 \\
\hline & Female & 7.5 & 7.4 & 0.950 & MMSE $<22$ & 7.8 & 6.9 & 0.579 & Nursing home & 5.3 & 7.7 & 0.471 \\
\hline \multirow{2}{*}{ Stroke } & Male & 8.7 & 6.0 & 0.043 & MMSE $\geq 22$ & 6.9 & 5.3 & 0.193 & Own house & 8.4 & 5.1 & 0.001 \\
\hline & Female & 7.9 & 4.8 & 0.025 & MMSE $<22$ & 9.3 & 5.0 & 0.002 & Nursing home & 8.0 & 7.1 & 0.772 \\
\hline \multirow{2}{*}{ Cerebral hemorrhage } & Male & 1.8 & 1.6 & 0.732 & MMSE $\geq 22$ & 1.2 & 1.2 & 0.547 & Own house & 1.8 & 1.4 & 0.410 \\
\hline & Female & 1.2 & 1.3 & 1 & MMSE $<22$ & 1.9 & 1.7 & 0.807 & Nursing home & 0 & 1.8 & 0.613 \\
\hline \multirow{2}{*}{ Epilepsy } & Male & 1.6 & 1.5 & 0.958 & MMSE $\geq 22$ & 1.2 & 1.3 & 1 & Own house & 1.8 & 1.3 & 0.287 \\
\hline & Female & 2.0 & 1.2 & 0.242 & MMSE $<22$ & 2.2 & 1.2 & 0.165 & Nursing home & 1.3 & 2.4 & 1 \\
\hline \multirow{2}{*}{ Migraine } & Male & 0.5 & 0.2 & 0.249 & MMSE $\geq 22$ & 0.9 & 0.4 & 0.165 & Own house & 0.7 & 0.3 & 0.138 \\
\hline & Female & 1.6 & 0.4 & 0.580 & MMSE $<22$ & 1.1 & 0.2 & 0.034 & Nursing home & 2.7 & 0.2 & 0.045 \\
\hline
\end{tabular}

Univariate comparisons were performed using either the chi-square or Fisher's exact test wherever appropriate. Statistically significant differences $(P<0.05)$ in bold. AD, Alzheimer's disease; DLB, dementia with Lewy bodies; MMSE, Mini-Mental State Examination.

neuropathological study that included 96 DLB patients, no lesions of ischemic strokes were present in these subjects. The study suggested that the diagnosis of DLB had a protective effect against stroke [33]. Another study suggested that DLB patients with advanced typical Lewy body pathology were less likely to have history of stroke and cerebrovascular diseases [34]. This study revealed that infarcts, atherosclerosis and small vessel disease were inversely correlated to the extent of the DLB pathology. Nevertheless, cerebral amyloid angiopathy was associated with the grade of DLB pathology. A neuropathological case report revealed severe cerebral amyloid angiopathy in the presence of DLB pathology [35]. However, it can be argued that cerebral amyloid angiopathy is not related to DLB, but rather is a sign of pathological aging and concomitant $\mathrm{AD}[36,37]$.

Even though the reasons are not clear, our study strengthened by a large sample size - revealed a significantly frequent occurrence of stroke, specifically cerebral infarctions in DLB patients. More research is thus crucial to further elucidate this association. It can be speculated that the use of antipsychotics may have contributed to the development of strokes [38]. It is of interest that a considerable proportion of DLB patients were treated with antipsychotic medication before they were diagnosed with dementia (16\%). This could be due to the clinical presentation of DLB, in which, in contrast to $\mathrm{AD}$, frequent visual hallucinations are common early in the disease process.

Underlying psychiatric disorders may also be confounders [39] and lead to need for antipsychotics. It has been shown that antipsychotic treatment in dementia is associated with worse outcomes such as shorter time to nursing home admission, cerebrovascular events and mortality in older people $[4,40-42]$. The Swedish guidelines for the treatment of neuropsychiatric symptoms in dementia therefore state that antipsychotics should be used very restrictively and only for psychotic symptoms or aggression that causes suffering or potential danger to the patient or others [20]. However, they are often prescribed to older people with dementia $[43,44]$, particularly in the nursing home setting $[45,46]$.

Cardiovascular comorbidities are frequent in all dementia disorders $[47,48]$ and belong to commonly reported causes of death [49]. In our study they have been found more common in the DLB group compared with AD, 
particularly in female patients, those who live in their own house and have a lower cognitive status at the beginning of the diagnostic process. A recent nationwide study in Sweden revealed that $60 \%$ of DLB patients were treated with cardiovascular medication, but the use of these drugs was lower in this group compared with AD [47]. However, this difference may be attributed to the fear of side effects in DLB patients; for example, side effects due to autonomic dysfunction. AD patients present the lowest mortality rate compared with other dementia disorders [7] and are therefore considered the healthiest group of dementia patients [50], even though there are some contradictory reports [51,52]. Investigating comorbidities in patients with dementia can provide with valuable insights into dementia disorders and contribute to better understanding of their pathophysiology.

\section{Limitations and strengths}

One may criticize that the study is limited by the validity of diagnoses. However, the validity of the Swedish National Patient Registry has been shown to be high for many diagnoses [53]. Nevertheless, the underestimation of comorbidities is inevitable since the Swedish National Patient Registry is based on outpatient or inpatient referrals and those with mild symptoms who did not seek medical help are not recorded. The validity of the data in SveDem has been assessed, especially in memory clinics. The data registered in memory clinics in a random sample of patients were in good agreement with medical records in a validation process [54]. Moreover, although we considered timing for the events, the probability of reverse causation is not completely omitted.

The validity of the diagnosis of dementia disorders has not been examined. It is necessary to acknowledge that the way of diagnosing both dementia types in SveDem reflects clinical practice in Sweden, and biomarkers such as dopamine transporter single-photon emission computed tomography is not available at all centers. Symptoms of DLB and AD overlap, which leads to difficulties in the diagnostic process. Autopsy diagnosis is currently not available but many patients are followed longitudinally, which probably improves diagnostic accuracy. Linking SveDem to autopsy records in future could help assess the accuracy of the clinical diagnoses.

Our study benefits from one of the largest samples of DLB patients in the world. Most of the previous studies have focused either on a single or a small number of comorbidities, while we compared the entire comorbidity profile. Using the exact date of registration for each comorbidity and dementia, we had access to the consecutive timing of the events in order to determine whether comorbidities occurred either before or after dementia diagnosis. Both SveDem and the Swedish National Patient Registry have just a minute proportion of missing values.
The personal registration number makes it possible to follow each individual over time and to connect corresponding information from different registries in Sweden. The number of hospital stays with missing personal registration numbers in the inpatient registry was only $0.6 \%$ in 2006 [53].

\section{Conclusions}

Our study indicated a worse comorbidity profile in DLB patients, with a higher prevalence of depression, stroke and migraine, compared with the AD population. Deeper knowledge about these differences among the DLB and $\mathrm{AD}$ groups is needed. Future studies could explore whether the presented associations are due to different mechanisms of these disorders as well as studying their influence on diagnostics and care.

\section{Abbreviations \\ AD: Alzheimer's disease; Cl: confidence interval; DLB: dementia with Lewy bodies; ICD: International Classification of Diseases; MMSE: Mini-Mental State Examination; OR: odds ratio; SD: standard deviation; SveDem: Swedish Dementia Registry.}

\section{Competing interests}

The authors declare that they have no competing interests.

\section{Authors' contributions}

S-MF was involved in the conception, design and acquisition of data and carried out analysis, interpreted the results and wrote the manuscript. SD contributed to the conception and carried out data mining, analysis and writing of the manuscript. PC participated in the interpretation of the findings, writing of the manuscript and substantial contribution to its content. DA participated in the interpretation of the findings and revised the manuscript critically for important intellectual content. ME conceived of the study, and contributed to its design and coordination and to critical improvement of the manuscript. DR made substantial contributions to conception, design and acquisition of data, participated in the interpretation of the findings and revised the manuscript critically. All authors read and approved the final manuscript.

\section{Acknowledgements}

The authors are grateful to SveDem [12] for providing data for this study as well as many thanks to all participants in SveDem (patients, caregivers and staff). This study was supported financially by the Swedish Brain Power network, the Swedish Association of Local Authorities and Regions, and the Stockholm County Council. DR was supported by the Swedish Research Council (grant 2012-2291), the Swedish Society of Medicine and Alzheimerfonden.

\section{Author details}

'Division of Clinical Geriatrics, Department of Neurobiology, Care Sciences, and Society, Center for Alzheimer Research, Karolinska Institutet, Stockholm, Sweden. ${ }^{2}$ Division of Neurogeriatrics, Department of Neurobiology, Care Sciences, and Society, Center for Alzheimer Research, Karolinska Institutet, Stockholm, Sweden. International Clinical Research Center and St. Anne's University Hospital, Brno, Czech Republic. ${ }^{4}$ Centre for Age-Related Diseases, Stavanger University Hospital, Stavanger, Norway. ${ }^{5}$ Department of Geriatric Medicine, Karolinska University Hospital, Stockholm, Sweden.

Received: 30 April 2014 Accepted: 5 September 2014

Published online: 06 October 2014

\section{References}

1. Kalra S, Bergeron C, Lang AE: Lewy body disease and dementia. A review. Arch Intern Med 1996, 156:487-493. 
2. Vossius C, Testad I, Skjaeveland R, Nesvag S: The use and costs of health and social services in patients with longstanding substance abuse. $B M C$ Health Serv Res 2013, 13:185.

3. Oesterhus R, Soennesyn H, Rongve A, Ballard C, Aarsland D, Vossius C: Long-term mortality in a cohort of home-dwelling elderly with mild Alzheimer's disease and Lewy body dementia. Dement Geriatr Cogn Disord 2014, 38:161-169.

4. Rongve A, Vossius C, Nore S, Testad I, Aarsland D: Time until nursing home admission in people with mild dementia: comparison of dementia with Lewy bodies and Alzheimer's dementia. Int J Geriatr Psychiatry 2014, 29:392-398.

5. Gill DP, Hubbard RA, Koepsell TD, Borrie MJ, Petrella RJ, Knopman DS, Kukull WA: Differences in rate of functional decline across three dementia types. Alzheimers Dement 2013, 9:S63-S71.

6. Espallargues M, Philp I, Seymour DG, Campbell SE, Primrose W, Arino S, Dunstan E, Lamura G, Lawson P, Mestheneos E, Politynska B, Raiha I, ACMEplus PROJECT TEAM: Measuring case-mix and outcome for older people in acute hospital care across Europe: the development and potential of the ACMEplus instrument. QJM 2008, 101:99-109.

7. Garcia-Ptacek S, Farahmand B, Kareholt I, Religa D, Cuadrado ML, Eriksdotter M: Mortality risk after dementia diagnosis by dementia type and underlying factors: a cohort of 15,209 patients based on the Swedish dementia registry. J Alzheimers Dis 2014, 41:467-477.

8. Ballard C, Holmes C, McKeith I, Neill D, O'Brien J, Cairns N, Lantos P, Perry E, Ince P, Perry R: Psychiatric morbidity in dementia with Lewy bodies: a prospective clinical and neuropathological comparative study with Alzheimer's disease. Am J Psychiatry 1999, 156:1039-1045.

9. Boot BP, Orr CF, Ahlskog JE, Ferman TJ, Roberts R, Pankratz VS, Dickson DW, Parisi J, Aakre JA, Geda YE, Knopman DS, Petersen RC, Boeve BF: Risk factors for dementia with Lewy bodies: a case-control study. Neurology 2013, 81:833-840.

10. Sadak TI, Katon J, Beck C, Cochrane BB, Borson S: Key neuropsychiatric symptoms in common dementias: prevalence and implications for caregivers, clinicians, and health systems. Res Gerontol Nurs 2014, 7:44-52.

11. Fritze F, Ehrt U, Hortobagyi T, Ballard C, Aarsland D: Depressive symptoms in Alzheimer's disease and lewy body dementia: a one-year follow-up study. Dement Geriatr Cogn Disord 2011, 32:143-149.

12. Swedish Dementia Registry [www.svedem.se]

13. Religa D, Spangberg K, Wimo A, Edlund AK, Winblad B, EriksdotterJonhagen M: Dementia diagnosis differs in men and women and depends on age and dementia severity: data from SveDem, the Swedish Dementia Quality Registry. Dement Geriatr Cogn Disord 2012, 33:90-95.

14. Skoldunger A, Wimo A, Johnell K: Net costs of dementia in Sweden - an incidence based 10 year simulation study. Int J Geriatr Psychiatry 2012, 27:1112-1117

15. WHO: The ICD-10 Classification of Mental and Behavioral Disorders: Diagnostic Criteria for Research. Geneva: World Health Organization; 1993.

16. McKeith IG, Dickson DW, Lowe J, Emre M, O'Brien JT, Feldman H, Cummings J, Duda JE, Lippa C, Perry EK, Aarsland D, Arai H, Ballard CG, Boeve B, Burn DJ, Costa D, Del Ser T, Dubois B, Galasko D, Gauthier S, Goetz CG, Gomez-Tortosa E, Halliday G, Hansen LA, Hardy J, Iwatsubo T, Kalaria RN, Kaufer D, Kenny RA, Korczyn A: Diagnosis and management of dementia with Lewy bodies: third report of the DLB Consortium. Neurology 2005, 65:1863-1872

17. Folstein MF, Folstein SE, McHugh PR: Mini-mental state. A practical method for grading the cognitive state of patients for the clinician. J Psychiatr Res 1975, 12:189-198.

18. Razavi D, Ljung R, Lu Y, Andren-Sandberg A, Lindblad M: Reliability of acute pancreatitis diagnosis coding in a National Patient Register: a validation study in Sweden. Pancreatology 2011, 11:525-532.

19. Armitage $\mathrm{JN}$, van der Meulen $\mathrm{JH}$ : Identifying co-morbidity in surgical patients using administrative data with the Royal College of Surgeons Charlson Score. Br J Surg 2010, 97:772-781.

20. Gordon M, Stark A, Skoldenberg OG, Karrholm J, Garellick G: The influence of comorbidity scores on re-operations following primary total hip replacement: comparison and validation of three comorbidity measures. Bone Joint J 2013, 95-B:1184-1191.

21. Fereshtehnejad SM, Religa D, Westman E, Aarsland D, Lokk J, Eriksdotter M: Demography, diagnostics, and medication in dementia with Lewy bodies and Parkinson's disease with dementia: data from the Swedish
Dementia Quality Registry (SveDem). Neuropsychiatr Dis Treat 2013, 9:927-935.

22. McKeith I, Del Ser T, Spano P, Emre M, Wesnes K, Anand R, Cicin-Sain A, Ferrara R, Spiegel R: Efficacy of rivastigmine in dementia with Lewy bodies: a randomised, double-blind, placebo-controlled international study. Lancet 2000, 356:2031-2036.

23. Wang HF, Yu JT, Tang SW, Jiang T, Tan CC, Meng XF, Wang C, Tan MS, Tan $L$ : Efficacy and safety of cholinesterase inhibitors and memantine in cognitive impairment in Parkinson's disease, Parkinson's disease dementia, and dementia with Lewy bodies: systematic review with meta-analysis and trial sequential analysis. I Neurol Neurosurg Psychiatry 2014, [Epub ahead of print].

24. Aarsland D, Ballard C, Walker Z, Bostrom F, Alves G, Kossakowski K, Leroi I, Pozo-Rodriguez F, Minthon L, Londos E: Memantine in patients with Parkinson's disease dementia or dementia with Lewy bodies: a double-blind, placebo-controlled, multicentre trial. Lancet Neurol 2009, 8:613-618.

25. Andreasen $P$, Lonnroos $E$, von Euler-Chelpin MC: Prevalence of depression among older adults with dementia living in low- and middle-income countries: a cross-sectional study. Eur J Pub Health 2014, 24:40-44.

26. Iranzo A, Gelpi E, Tolosa E, Molinuevo JL, Serradell M, Gaig C, Santamaria J: Neuropathology of prodromal Lewy body disease. Mov Disord 2014, 29:410-415

27. Chuang CS, Lin CL, Lin MC, Sung FC, Kao CH: Migraine and risk of dementia: a nationwide retrospective cohort study. Neuroepidemiology 2013, 41:139-145

28. Gudmundsson LS, Scher Al, Sigurdsson S, Geerlings MI, Vidal JS, Eiriksdottir G, Garcia MI, Harris TB, Kjartansson O, Aspelund T, van Buchem MA, Gudnason V, Launer L: Migraine, depression, and brain volume: the AGES-Reykjavik Study. Neurology 2013, 80:2138-2144.

29. Hagen K, Stordal E, Linde M, Steiner TJ, Zwart JA, Stovner LJ: Headache as a risk factor for dementia: a prospective population-based study. Cephalalgia 2014, 34:327-335.

30. Manford M, Andermann F: Complex visual hallucinations. Clinical and neurobiological insights. Brain 1998, 121:1819-1840.

31. Demarquay G, Ryvlin P, Royet JP: Olfaction and neurological diseases: a review of the literature. Rev Neurol 2007, 163:155-167.

32. Ballard C, O'Sullivan MJ: Alzheimer disease and stroke: cognitive and neuroimaging predictors of AD and stroke. Nat Rev Neurol 2013, 9:605-606.

33. Jellinger KA: Prevalence of vascular lesions in dementia with Lewy bodies. A postmortem study. J Neural Transm 2003, 110:771-778.

34. Isojima D, Togo T, Kosaka K, Fujishiro H, Akatsu H, Katsuse O, Iritani S Matsumoto T, Hirayasu Y: Vascular complications in dementia with Lewy bodies: a postmortem study. Neuropathology 2006, 26:293-297.

35. Mendel T, Bertrand E, Szpak GM, Stepien T, Wierzba-Bobrowicz T: Complications of severe cerebral amyloid angiopathy in the course of dementia with Lewy bodies. A case report. Folia Neuropathol 2010, 48:293-299.

36. Wu E, Lipton RB, Dickson DW: Amyloid angiopathy in diffuse Lewy body disease. Neurology 1992, 42:2131-2135.

37. Dugger BN, Adler CH, Shill HA, Caviness J, Jacobson S, Driver-Dunckley E, Beach TG, The Arizona Parkinson's Disease C: Concomitant pathologies among a spectrum of parkinsonian disorders. Parkinsonism Relat Disord 2014, 20:525-529.

38. Herrmann N, Mamdani M, Lanctot KL: Atypical antipsychotics and risk of cerebrovascular accidents. Am J Psychiatry 2004, 161:1113-1115.

39. Jaussent I, Ancelin ML, Berr C, Peres K, Scali J, Besset A, Ritchie K, Dauvilliers $Y$ : Hypnotics and mortality in an elderly general population: a 12-year prospective study. BMC Med 2013, 11:212

40. Langballe EM, Engdahl B, Nordeng H, Ballard C, Aarsland D, Selbaek G: Short- and long-term mortality risk associated with the use of antipsychotics among 26,940 dementia outpatients: a population-based study. Am J Geriatr Psychiatry 2014, 22:321-331.

41. Rochon PA, Normand SL, Gomes T, Gill SS, Anderson GM, Melo M, Sykora K, Lipscombe L, Bell CM, Gurwitz JH: Antipsychotic therapy and short-term serious events in older adults with dementia. Arch Intern Med 2008, 168:1090-1096.

42. Douglas IJ, Smeeth L: Exposure to antipsychotics and risk of stroke: self controlled case series study. BMJ 2008, 337:a1227. 
43. Johnell K, Religa D, Eriksdotter M: Differences in drug therapy between dementia disorders in the Swedish dementia registry: a nationwide study of over 7,000 patients. Dement Geriatr Cogn Disord 2013, 35:239-248.

44. Fereshtehnejad SM, Johnell K, Eriksdotter M: Anti-dementia drugs and co-medication among patients with Alzheimer's disease: investigating real-world drug use in clinical practice using the Swedish Dementia Quality Registry (SveDem). Drugs Aging 2014, 31:215-224.

45. Gustafsson M, Karlsson S, Gustafson Y, Lovheim H: Psychotropic drug use among people with dementia-a six-month follow-up study. BMC Pharmacol Toxicol 2013, 14:56.

46. Johnell K, Fastbom J: Comparison of prescription drug use between community-dwelling and institutionalized elderly in Sweden. Drugs Aging 2012, 29:751-758.

47. Cermakova P, Fereshtehnejad SM, Johnell K, Winblad B, Eriksdotter M, Religa D: Cardiovascular medication burden in dementia disorders: a nationwide study of 19,743 dementia patients in the Swedish Dementia Registry. Alzheimers Res Ther 2014, 6:34.

48. Cermakova P, Eriksdotter M, Lund LH, Winblad B, Religa P, Religa D: Heart failure and Alzheimer's disease. J Intern Med 2014, [Epub ahead of print].

49. Magaki S, Yong WH, Khanlou N, Tung S, Vinters HV: Comorbidity in dementia: update of an ongoing autopsy study. J Am Geriatr Soc 2014 62(9):1722-1728.

50. Imfeld P, Brauchli Pernus YB, Jick SS, Meier CR: Epidemiology, co-morbidities, and medication use of patients with Alzheimer's disease or vascular dementia in the UK. J Alzheimers Dis 2013, 35:565-573.

51. Hill JW, Futterman R, Duttagupta S, Mastey V, Lloyd JR, Fillit H: Alzheimer's disease and related dementias increase costs of comorbidities in managed Medicare. Neurology 2002, 58:62-70.

52. Eaker ED, Mickel SF, Chyou PH, Mueller-Rizner NJ, Slusser JP: Alzheimer's disease or other dementia and medical care utilization. Ann Epidemiol 2002, 12:39-45.

53. Ludvigsson JF, Andersson E, Ekbom A, Feychting M, Kim JL, Reuterwall C, Heurgren M, Olausson PO: External review and validation of the Swedish national inpatient register. BMC Public Health 2011, 11:450

54. Årsrapport SveDem 2012 [http://www.ucr.uu.se/svedem/index.php/ om-svedem/arsrapporter]

doi:10.1186/s13195-014-0065-2

Cite this article as: Fereshtehnejad et al:: Comorbidity profile in dementia with Lewy bodies versus Alzheimer's disease: a linkage study between the Swedish Dementia Registry and the Swedish National

Patient Registry. Alzheimer's Research \& Therapy 2014 6:65.

\section{Submit your next manuscript to BioMed Central and take full advantage of:}

- Convenient online submission

- Thorough peer review

- No space constraints or color figure charges

- Immediate publication on acceptance

- Inclusion in PubMed, CAS, Scopus and Google Scholar

- Research which is freely available for redistribution 